\title{
Evelin Witruk
}

University of Leipzig, Institute of Psychology

\section{Assessment and Treatment of Dyslexia - An Overview}

\section{Abstract}

This article will overview the current state-of-the-art of the different methods of assessment and treatment of dyslexia. On the basis of the modification and extension of the multilevel model of Valtin $(1989$, modified by Witruk, 1993) the methods were discussed regarding their main aims. Assessment and treatment methods were described regarding the primary causes (biological risk factors), secondary causes (partial performance deficits), primary symptoms (reading and writing failures) and regarding the secondary symptoms (emotional and behavioural disorders). Alternative methods are discussed.

Key words: Multilevel model of dyslexia, magnocellular deficit, partial performance deficit, working memory, complex training programme, alternative methods, Positive Psychology.

\section{Introduction}

The history of the dyslexia research is controversial and led to many contradictory theories and results up to the present day. It is now just over 110 years since Morgan (1896) first published his famous account of Percy, a dyslexic boy of 14 years. The state-of-the-art of dyslexia research can be characterised by the distinction of scientists in groups of protagonists of a visual versus a phonological/auditory deficit on the one hand and in groups of protagonists of a low, basic level versus a higher level deficit on the other hand. A lot of opposite results and theories lead to the question about the specificity and homogeneousity of different deficits in dyslexic individuals. The model of Habib (2000) gives an integration of perceptive and cognitive deficits on the basis of a common temporal processing deficit, which can be analysed on a low, basic level and/or on a higher complex level of performance. The individual combination of partial deficits on the low and the higher level produces the specificity of the symptoms.

Dyslexia is defined by the World Health Organisation (WHO) as a restricted developmental disorder in the acquisition of reading often connected with a disorder in acquisition of writing. These disorders are usually contrasted by the better, normal or over-averaged intelligence. During the last century hundreds of scientists searched the specific sources of these disabilities. A lot of opposite results lead to the question about the dyslexia specificity and subtype specificity of deficits. The different prevalence rates of dyslexia in the world varied from 1 $\%$ in Scandinavian countries, $2 \%$ around the region of Beijing, 3-5\% in Germany, 
8-10\% in UK and USA lead to the question of the cultural/language impact on the development of dyslexia. The relation of boys to girls is about 4:1.

\section{The multilevel model of dyslexia}

The multilevel model of dyslexia calls for two causal and two symptomatic levels which are superimposed in time, with one flowing from and having repercussions on the others (cf. Table 1).

Table 1. Multilevel model (developed by Valtin, 1989, modified by Witruk, 1993).

\begin{tabular}{|c|c|c|c|}
\hline & & Assessment & Treatment \\
\hline & Primary & Biological risk factors & Compensatory training \\
\hline \multicolumn{4}{|l|}{ Causes } \\
\hline & Secondary & Partial performance deficit & Training of basic functions \\
\hline & Primary & Reading and writing tests & $\begin{array}{l}\text { Rehabilitative exercises of } \\
\text { reading and writing }\end{array}$ \\
\hline \multicolumn{4}{|c|}{ Symptoms } \\
\hline & Secondary & $\begin{array}{l}\text { Personality questionnaire, } \\
\text { observation }\end{array}$ & $\begin{array}{l}\text { Complex training, Psycho- } \\
\text { therapy }\end{array}$ \\
\hline
\end{tabular}

On the level of primary causes, it is assumed that there exist biological risk factors interacting with environmental stressors and believed to express themselves in functional and structural neuro-anatomical characteristics of dyslexic individuals. The intervention on this level can aim at the compensation or at the restoration of these biological risk factors.

On the one hand, the secondary causes that grow out of the primary ones refer to partial performance deficits in the fields of visual and auditory perception, motor patterns and long-term and working memory. Here, the treatment involves a functional training, which is highly selected in the main imported deficit function and assumes a generalisation and stabilisation of the complex action system of reading and writing. In principle, the cause levels can be identified even before such children start formal education.

On the other hand, primary symptoms can be detected only in the specificity of failures in reading and orthography, for example on the basis of error, time and eye movement analyses. In time, these latent failures and the responses from these children's environment lead to a vicious circle of secondary symptoms made up of the four stages of anxiety, blocking, avoidance, compensation and lowering of motivation, as described by Betz and Breuninger (1982). These effects underscore the existential observational relevance of written language and the consequences 
of its impairments. Secondary symptoms may have repercussions on primary symptoms and on such causes as destabilisation and blocking, though there has hardly been any research on this yet.

Thus, the psychopathology of dyslexia provides some clues about possible working memory deficits and the way they must be integrated into a person's overall pattern of disability.

\section{Assessment and treatment regarding primary causes}

The genetic basis of dyslexia was discussed by the familial clustering and the concordance between parents and children ( $44 \%$ in Schulte-Koerne et al., 1998) and between monozygotic twins (90\%) in comparison to dizygotic twins (32\%). The primary reasons of dyslexia seem to be represented in genetic anomalies on the chromosomes 6 and 15 (Wilcke \& Boltze, 2010).

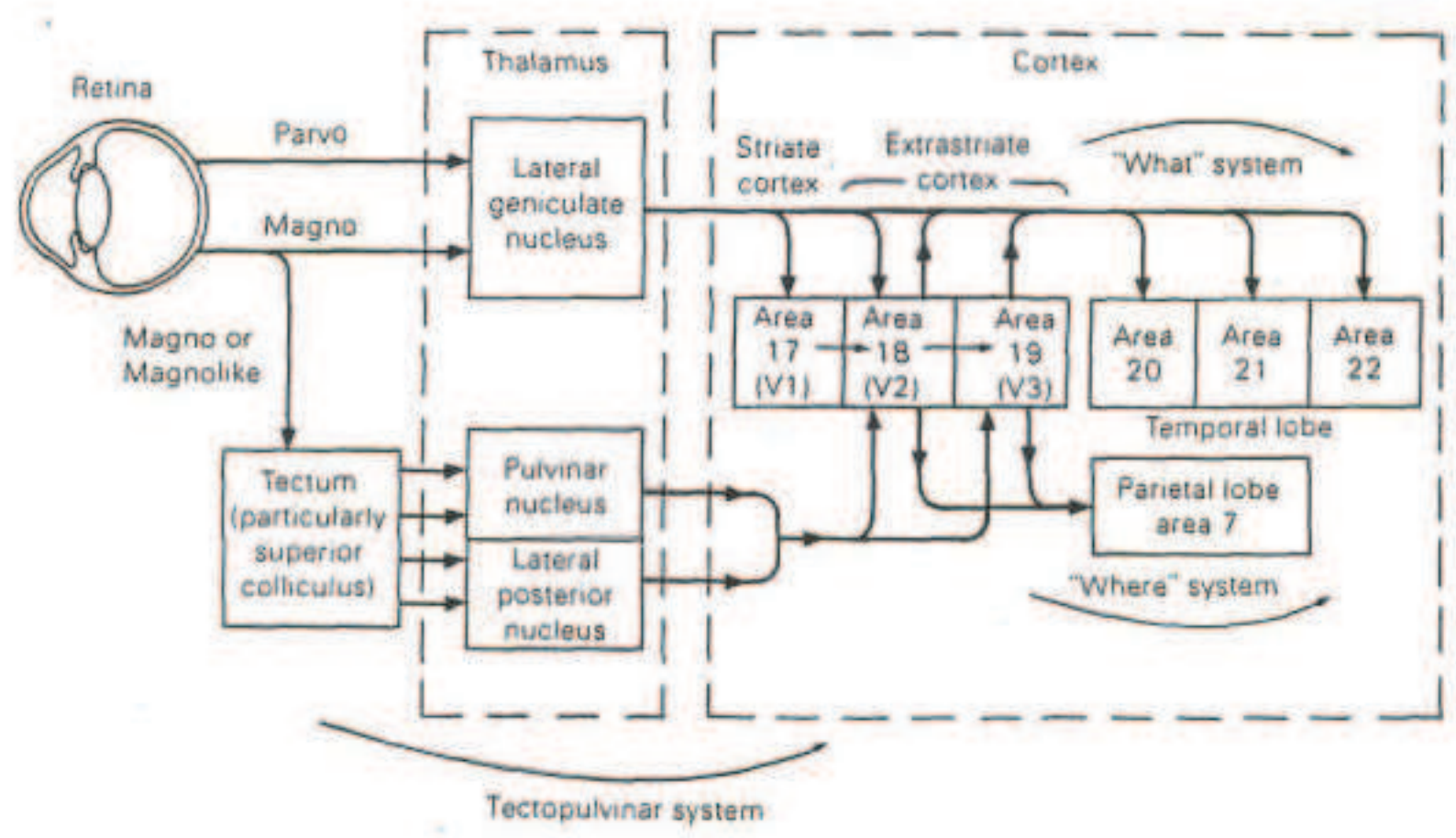

Figure 1. Schematic figure of the visual system.

The most spectacular evidence on the international research area has been presented by Galaburda and Livingstone (1993). They compared brain sections of 5 dead dyslexic adults with those of 7 healthy individuals of comparable age and occupations. When they compared these brains of each group, they detected disorganised magnocellular layers in the dyslexic geniculate laterale with smaller cells which seemed highly variable in size and shape. By contrast, they found no peculiarities in the parvocellular layers, which are mainly responsible for colour 
perception, while the magnocellular layers are responsible for contrast perception and hence the recognition of script (see Figure 1, 2).

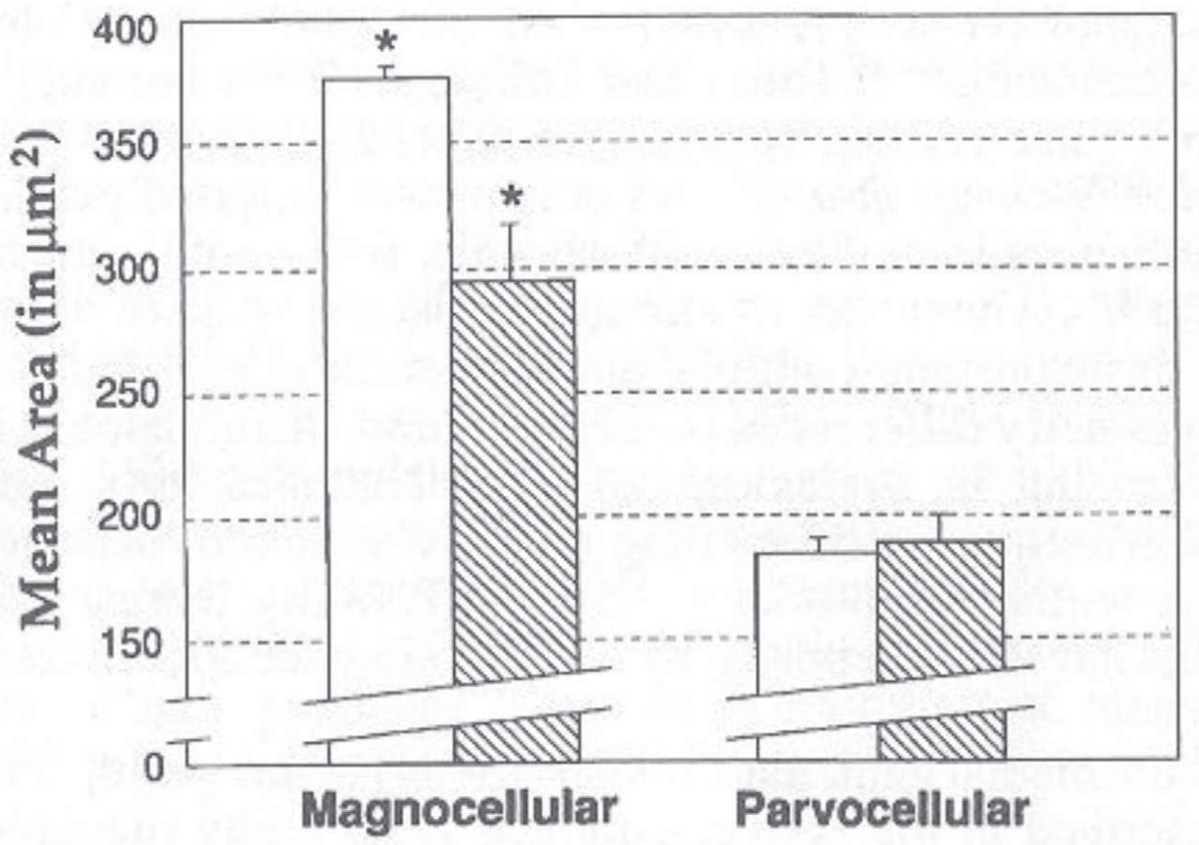

Figure 2. Significant smaller magnocells in dyslexic adults but the same size of parvocells (Galaburda \& Livingstone, 1993).

Regarding the magnocellular deficit hypothesis of dyslexia positive and negative evidence was presented. Our research included the interaction hypotheses of the magno- and the parvocellular systems measured by the visible persistence duration.

Visible persistence is one of the effects of the early or low level visual processing. Impairments of the early visual functions in dyslexics have been found with a variety of tasks, in particular with tasks involving dynamic stimuli like flicker fusion tasks and coherent, apparent and real motion perception tasks. Lower temporal and spatial contrast sensitivity and longer duration of visible persistence as deficits in dyslexics could be shown, which are linked to abnormalities in the magnocellular pathway. In this sense visible persistence is the amount of time for which a visual stimulus continues to be seen after it has been terminated. Breitmeyer and Ritter (1986) and Lovegrove (1996) suggested that after a saccade has been made from one fixation point to another, magno/transient channels inhibit parvo/sustain channels so that the previously fixated stimulus does not remain visible and mask the next stimulus which is fixated. Such masking would interfere with reading. When dyslexics' eyes move across a line, the high visible persistence masks the currently fixated text and makes it difficult to identify letters or words. Therefore the visual 
deficit can be explained on the basis of this theory as an inadequate inhibition of the parvocellular system by the magnocellular system. Studies of Lovegrove (1996), Slaghuis et al. (1996), Slaghuis and Ryan (1999) show an increased duration of visible persistence in dyslexics in comparison to normal readers. The authors explain the longer duration of visible persistence in dyslexia as a consequence of a disorder in transient channel inhibition of sustained channels. Cestnick and Coltheart (1999) could find no group and no subtype effect, but Slaghuis and Ryan (1999) could show a significant subtype effect of an increased visible persistence in dyslexics. Details concerning the Breitmeyer effect are shown in Figure 3.

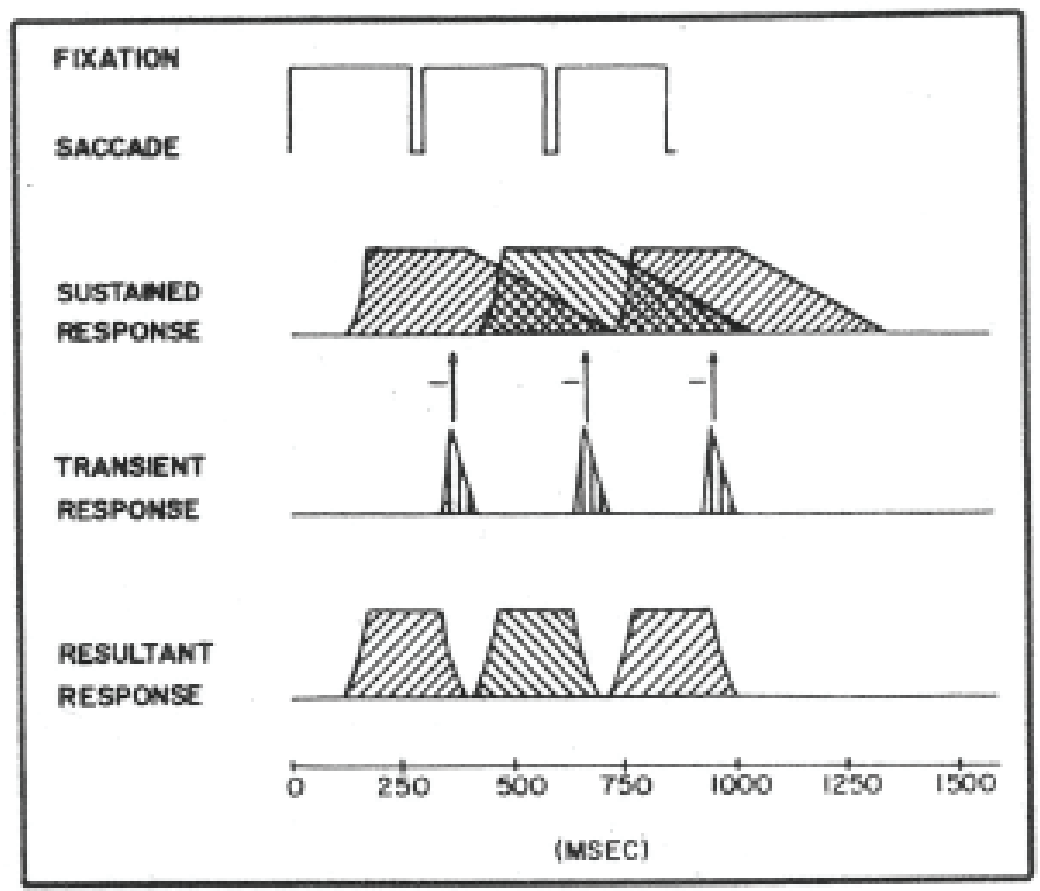

Figure 3. The Breitmeyer effect - interaction effect between the parvoand magno-system in the visual system [Note: Sustained Response = Parvo System (P); Transient Response = Magno System (M)].

In our experiments the role of visible persistence in dyslexia as a biological factor, which is cultural independent, was investigated by using the Ternus apparent movement tasks, which are used as a measure of duration of the visible persistence and as an index of the integrity of functioning of sustained and transient channels in dyslexia. Only in one of three subtypes of dyslexia we could find a significant increased visible persistence as a biological risk factor for the "smear over effect", which was first found by Breitmeyer and Ritter (1986).

A very strong other assumption has been developed during the last twenty years about the hemispheric co-ordination deficit in dyslexia. Research by Larsen, 
Hoien, Lundberg and Odegaard (1990) pointed to symmetric patterns of the left and right Planum Temporale in 15-year-old dyslexic children, who also had phonological deficits and who were either left-handed or both left- and righthanded somewhat more frequently than a control group. For the diagnostics it is possible to estimate the hemispheric co-ordination and dominance relation by the Hand Dominance Test (HDT) developed by Lienert (1976).

An additional biological basis of dyslexia was found by Robinson (2001) regarding an immune system dysfunction in the visual deficit subtype of dyslexia, indicating differences in connective tissue turnover due to infection or stress, which can cause a macular degeneration of the eye.

Examples of treatment methods regarding primary reasons are the following ones:

- Coloured glasses, transparencies and coloured paper of books should reduce the contrast and therefore the magnocellular activation. A compensation of the magnocellular deficit is expected.

- Reading windows should reduce the Breitmeyer- or "smear over effect".

- Prism glasses were developed for the stabilisation of the fixation point on the line.

- The cinesiological training like the "Brain Gym" program from Dennison and Dennison (1991) is based on the assumption of a hemispherical coordination deficit and wants to activate both hemispheres in the same time by special body exercises (e.g. symmetrical and cross-middle movements of the arms and legs).

- Dietary intervention, targeting specific biochemical anomalies were also investigated as a feasible treatment option.

\section{Assessment and treatment regarding secondary causes - Partial performance deficits}

The secondary causes of dyslexia were proofed in partial deficits in basic functions and not in complex actions of reading and writing. In principle, primary and secondary causes can be identified even before such children start formal education. Intervention and prevention can therefore also start before. Partial deficits can involve auditory and/or visual perception, tactile perception, working memory, long-term memory, motor functions and integration functions (Figure 4).

Partial deficits are related to basic functions, which are preconditions for higher complex activities like language, reading and writing (Figure 5). 


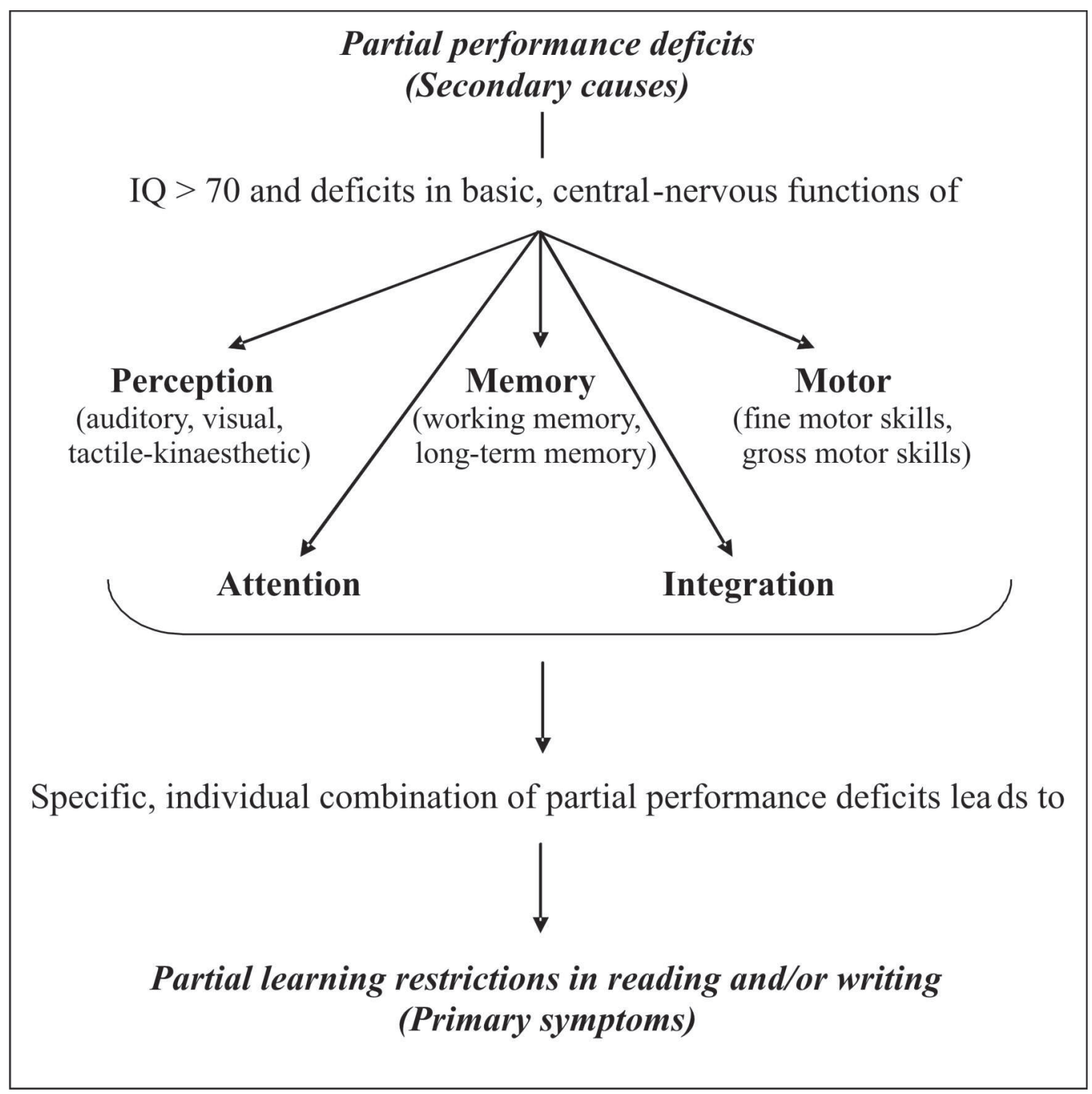

Figure 4. Partial performance deficits.

The results regarding the deficits of auditory or phonological working memory seem to be present with relatively high consistency (Witruk \& Ho, in prep., 2011). Deficits of visual working memory appear to depend strongly on the types of material used. Studies in which visual but nameable stimuli were used could be related to phonological decoding and to the phonological loop. The lower automation of Central Executive processes in dyslexics can be verified.

Impairment of working memory performance in dyslexic children and adults has been found for visual and auditory presentation of stimuli with different paradigms and types of material. 


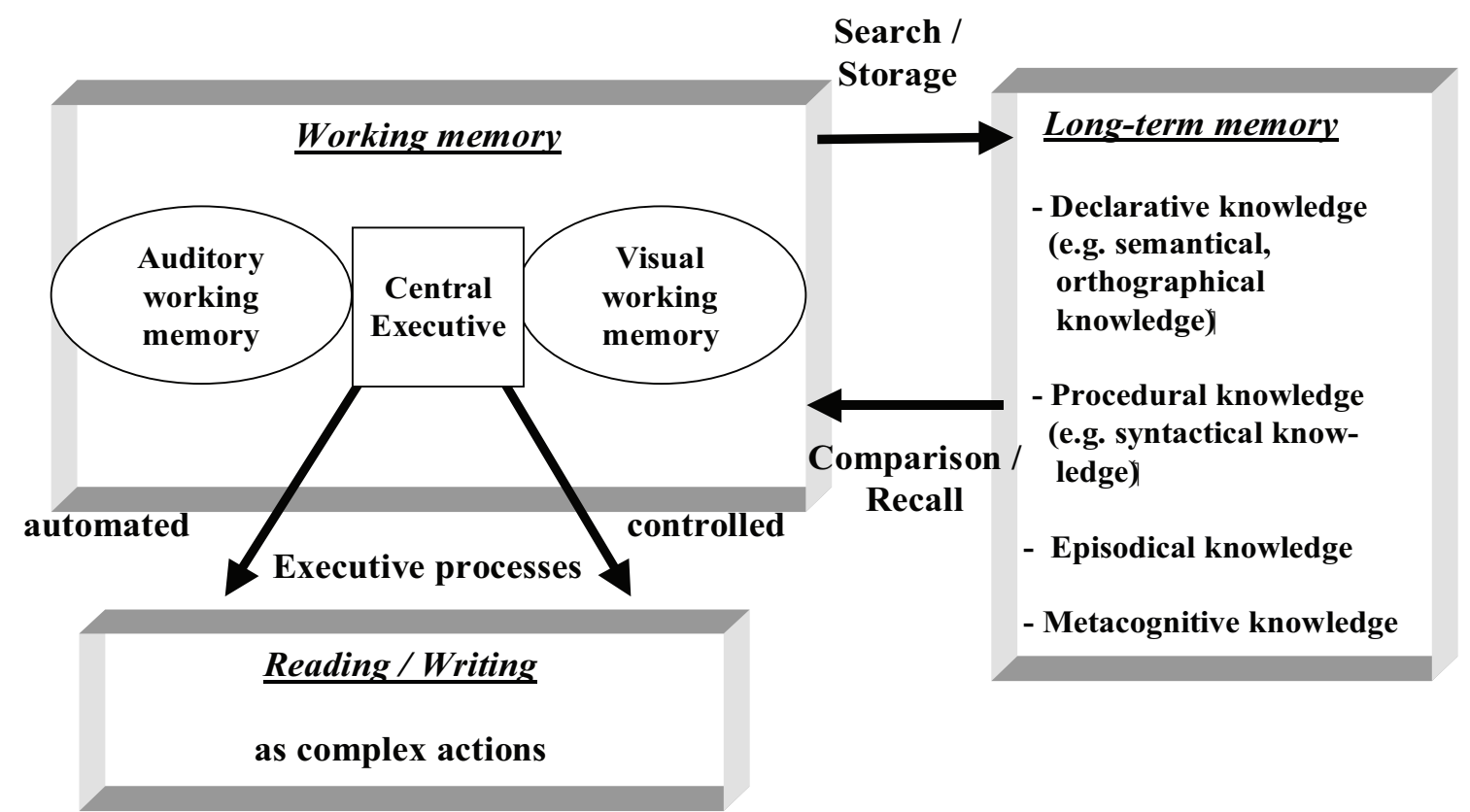

Figure 5. Working memory functions during reading and writing (Witruk, 2003).

\section{Examples of intervention regarding secondary causes}

Tachistoscopic visual perception training (Gutezeit, 1977) is based on a very short presentation $(0.5 \mathrm{sec}$.) of single words and word groups, which can be repeated until the child or the children group can read or write them. The training can be realized by an overhead projector or by a PC with LCD projector. Gutezeit has evaluated this training for dyslexic children of the $3^{\text {rd }}$ grade and found significant improvements of the reading and writing performance.

- Working memory training (Witruk, 2003)

- Visual perception training (Frostig, 1974)

- Training of integration functions (Karma, 2003)

\section{Assessment and treatment of primary symptoms - Failures in reading and writing}

The diagnostic criteria in the ICD 10 are based on the analysis of failures in reading and writing in comparison to a better intelligence. This discrepancy between the $\mathrm{IQ}$ and reading and writing performance is the basic assumption. Sometimes this discrepancy is quantified. The typical errors in reading and writing are:

- Loss of letters, word parts, whole words,

- Reversal errors of letters or mirror errors (like " $u$ " and " $n$ ", "b" and "d"),

- Adding of letters, word parts or whole words, 
- Low reading speed,

- Low level of reading understanding.

For the assessment of the primary symptoms it is necessary:

- to measure the reading performance with a reading test (for example the Zurich Reading Test (ZRT) from Linder and Grissemann, 2000),

- to measure the writing performance with a writing test (for example the Westermann writing test (WRT 6+) from Rathenow, Vöge and Laupenmühlen, 1980),

- to use a combined reading and writing test like the Salzburg reading and writing test (SLRT) from Landerl, Wimmer, \& Moser (1997) and

- for the proof of the discrepancy to use an intelligence test like the Cultural Fair Test (CFT) from Weiss (1987).

\section{Intervention regarding primary symptoms}

Special rehabilitative classes ( $2^{\text {nd }}$ and $3^{\text {rd }}$ grade) offer particular didactics developed by Weigt (1994) with script oriented playing therapy, with additional supporting hand signals, graphical signs for peculiarities of orthography and with a morphemic rule system for the better understanding of the construction of the German script. These special rehabilitative classes were evaluated by Witruk (1993). A very good impact on the school career and the personality development of the dyslexic children could be found.

Private reading and writing learning institutes offer special didactics and an individual assessment and suport.

\section{Assessment and treatment of secondary symptoms}

Secondary symptoms can be developed in dependence on the feedback of the environment. The interactive behaviour of parents, peers and teachers with the dyslexic child has a high relevance for its self-esteem. The labilisation and the decrease of the self-esteem are the beginning of the development of emotional and behavioural disorders.

Betz and Breuninger (1982) describe four stages of the development of emotional and behavioural disorders:

1. After the first weeks in school negative attributions (of the failures) developed by the child and by the environment are starting. The first supporting activities by the parents will be experienced by the child as repression.

2. The dyslexic child tries to get success by the producing of compensating behaviour like clownery, violent behaviour or stealing presents for peers. But often the environment can not accept this behaviour and punishes it. 
3. In the third stage the anxiety increases and leads to avoidance behaviour like absence from school, blocking and avoidance of reading and writing demands.

4. In the fourth stage these disordered emotions and behaviour will be stabilized by the decrease of motivation, disidentification and the misunderstanding of the environment (for example the mistrust of parents in cases of successful performance of the child).

If a dyslexic child has reached this fourth stage it is not possible to exercise reading and writing but it is necessary to reduce the disordered behaviour and the anxiety and to stabilize its self-esteem. That means a psychotherapy or a complex program including the parents are strongly recommended.

\section{Intervention regarding secondary symptoms}

The complex training programme developed by Betz and Breu-ninger(1982) is integrating three modules (Figure 6, Table 2): (1) Group psychotherapy with children differentiated in children with high anxiety and children with violent behaviour, (2) Parent working meetings with psycho-education, exchange of experiences and information about the progress of the intervention, (3) Training of the orthography by using special didactics of success (for example exercise by self-control system, optimization of the learning organization, registration of correct responses - not of errors - in the dictate).

Table 2. Course of the Complex training programme.

\begin{tabular}{|c|c|c|}
\hline Duration & Parents & Dyslexic children \\
\hline 3 months & $\begin{array}{l}\text { Introduction, psycho-education, } \\
\text { self-experience group } \\
\text { (1 meeting per week) }\end{array}$ & \\
\hline 2-3 months & $\begin{array}{l}\text { Self-experience group, } \\
\text { attendance and support for the } \\
\text { psychotherapy of the child } \\
\text { ( } 2 \text { meetings per month, later } 1 \\
\text { meeting per month) }\end{array}$ & $\begin{array}{l}\text { Psychological group } \\
\text { therapy (groups of } \\
\text { anxious and violent } \\
\text { children) } \\
\text { (1 meeting per week) } \\
\end{array}$ \\
\hline 9 months & $\begin{array}{l}\text { Self-experience group, } \\
\text { attendance and support for the } \\
\text { psychotherapy of the child } \\
\text { (1 meeting per } 6 \text { weeks) }\end{array}$ & $\begin{array}{l}\text { Spelling learning therapy } \\
\text { groups } \\
\text { ( } 1 \text { meeting per week) }\end{array}$ \\
\hline
\end{tabular}


Beside this Complex training programme exist single- or group psychotherapy of dyslexic children (client-centred, non-directive psychotherapy, behaviour therapy or psychoanalyses) or systemic therapy (integrating the whole family).

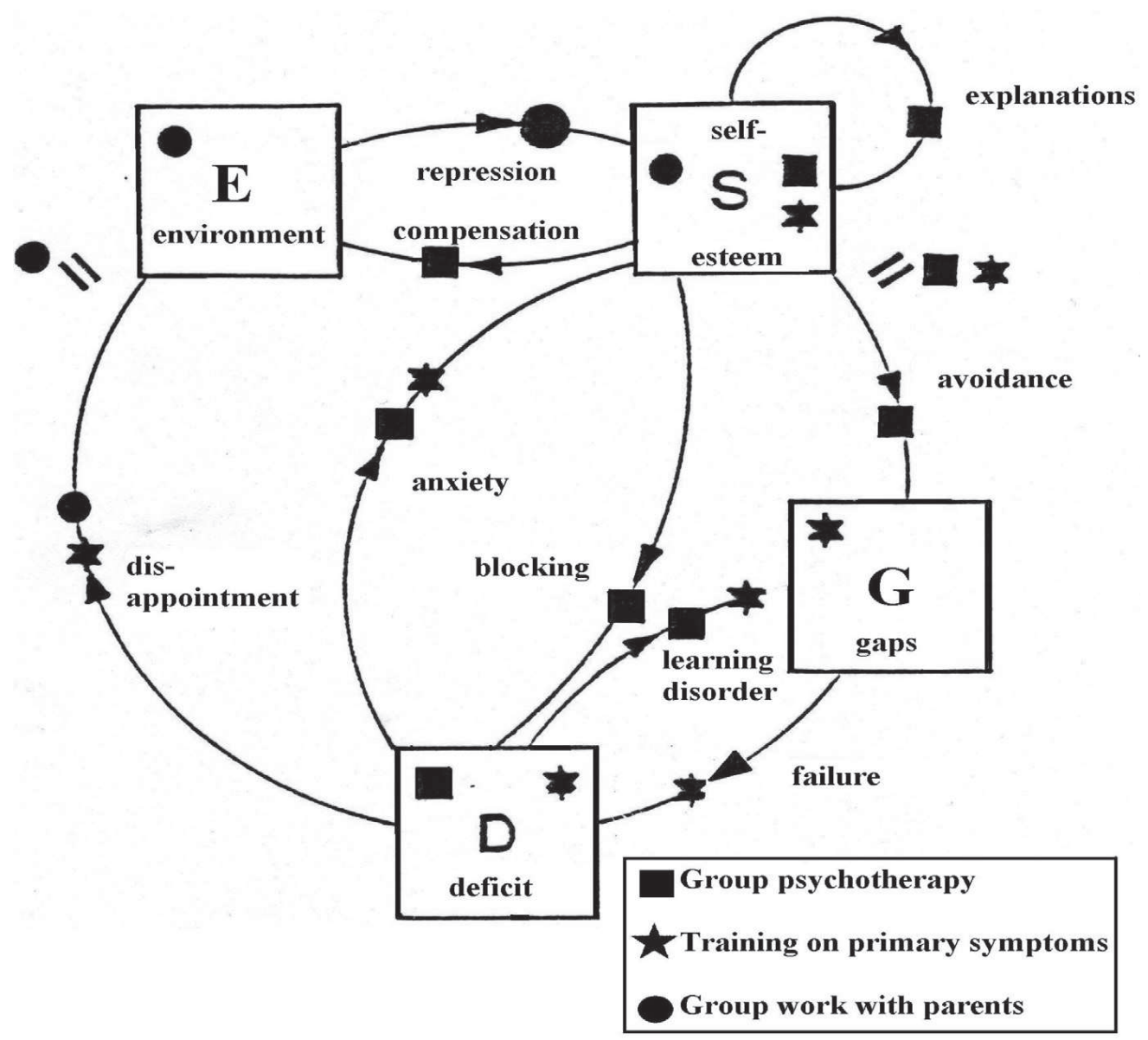

Figure 6. Complex training programme developed by Betz and Breuninger (1982).

\section{Alternative methods}

Alternative methods are not or not only based on the deficit assumption. They assume that dyslexic individual have special resources, compensation effects or talents. These alternative methods were developed by the traditional and secondary progressive education. For example, the Montessori material is useful, with letters consisting of different, unusual material like skin. Also, in the Waldorf education the eurythmics was developed, where the dyslexic children are dancing, singing and explaining letters and words. From secondary progressive education the implicit learning method "Learning to read by learning to write" is known. The table with the pictures and the association to letters should be used by dyslexics as a supportive method but not as a basic method. 
Other implicit learning methods are Learning by doing/moving, Learning by playing, Learning by sleeping, Holistic-sensory and activity oriented lessons, and Suggestopedia which are useful for dyslexics because they have some advantages comparing to explicit, traditional learning methods: Consciousness, attention, intention, planning, goal orientation and effort is not necessary for their functioning.

Holistic-sensoric and activity oriented lessons are realised in the progressive education and in the Experience education. It is based on the following principles: (1) activating as much as possible senses, (2) bodily movements and gestures, (3) interactive learning with others, (4) symmetrical interaction between teacher and student, (5) learning in natural environment, (6) personality development instead of solely knowledge acquisition, (7) active experiences (episodic knowledge instead of solely declarative knowledge).

The Davis learning method is a resource oriented approach and based on the assumption of special dyslexic talents. These special dyslexic talents obviously exist in higher level of visual-spatial and pictorial thinking with high intuition and creativity as well as in higher imaginary abilities. With an experimental discrimination design of possible and impossible figures Witruk, Winkler, and Guenther (in prep., 2011) could show a significant better performance of dyslexic adolescents (lower reaction times and less errors) comparing with nondyslexic adolescents of the same age and intelligence. Based on this material a visual-spatial ability test for measuring specific dyslexic talents is going to be prepared (Witruk, in prep., 2012).

As dyslexic adult, Davis (2000) developed his training method on the basis of his own school failures and frustrations. This training is using the special dyslexic talents of imagination and symbolisation. It works with pictorial imagination and abstract symbolisation and reduces the learning inhibitoric mechanisms of desorientation and confusion.

The Positive Psychology approach is based on the theory of Seligman and Csikszentmihalyi (1998) and the belief that "a psychology of positive human functioning will arise that achieves a scientific understanding and effective interventions to build thriving in individuals, families, and communities." The Positive Psychology is investigating and improving positive aspects of the human life like happiness, optimism, safety, trust, forgiveness, and solidarity in contrast to the conflict and disorders oriented traditional Psychology.

An application of Positive Psychology for dyslexic children is to find in Thomson and Hartley (1980). They compared dyslexic and nondyslexic children regarding their self-esteem, happiness, self-concept about reading, kindness, hardworking, intelligence and success. The dyslexic children show a stronger significant association between their self-concept of reading and happiness.

Tsang and Leung (2005/6) integrated in their study three secondary schools including dyslexic children in Hong Kong. Their treatment includes positive 
psychological methods in a home-school cooperation project. They show that the feelings of being understood and accepted can bring confidence and improvements in study attitude and even enhance performance in dyslexic children. This study can show the encouraging progress of dyslexic students.

Most of the alternative methods are oriented on the reduction or on the prevention of secondary symptoms. In addition, they want to support the reading and writing acquisition process.

\section{Conclusions}

On the basis of the modified and extended multilevel model of Valtin (1989, modified by Witruk, 1993) the different methods of assessment and treatment of dyslexia were discussed. For practical issues it is important to assess the primary causes (biological risk factors), secondary causes (partial performance deficits), primary symptoms (reading and writing failures) and secondary symptoms (emotional and behavioural disorders). On this basis the treatment methods can and should be selected systematically. In adition alternative methods can be used for prevention of secondary symptoms and for supportng of the reading and writing acqusition.

\section{References}

1. Betz, D., \& Breuninger, H. (1982). Teufelskreis Lernstörung. München: PVU.

2. Breitmeyer, B. G., \& Ritter, A. (1986). Visual persistence and the effect of eccentric viewing, element size, and frame duration on bistable stroboscopic motion percepts. Perception \& Psychophysics, 39 (4), pp. 275-280.

3. Cestnick L., \& Coltheart M. (1999). The relationship between language processing and visual processing in developmental dyslexia. Cognition, 30, 71(3), pp. 231-255.

4. Dennison, P. E., \& Dennison, G. (1991). Lehrerhandbuch Brain-Gym. Freiburg.

5. Davis, R. D. (2000). Legasthenie als Talentsignal. München: Ariston Verlag.

6. Frostig, M. (1974). Visuelle Wahrnehmungsförderung. Übungs-und Beobachtungsfolge für den Elementar- und Primarbereich. Anweisungsheft und Heft 1 - 3. (für deutsche Verhältnisse bearbeitet und herausgegeben von Anton und Erika Reinartz). Hannover: Schroedel.

7. Galaburda, A.M., \& Livingstone, M. (1993). Evidence for a Magnocellular Defect in Developmental Dyslexia. In P.Tallal, A. M. Galaburda, R. R. Llinás, \& C. von Euler (Eds.), Temporal Information Processing in the Nervous System: Special Reference to Dyslexia and Dysphasia. Annals of the New York Academy of Sciences. Vol. 682, New York: The New York Academy of Sciences, pp. 70-82.

8. Gutezeit, G. (1977). Projektionstachistoskopisches Übungsprogramm für leserechtschreibschwache Schüler. Göttingen: Hogrefe.

9. Habib, M. (2000). The neurological basis of developmental dyslexia: An overview and working hypothesis. Brain, 123 (12), pp. 2373-2399. 
10. Karma, K. (2003). AUDILEX 2.0 (Deutsche Bearbeitung von Bernd Richter). Helsinki: Comp-Aid Ltd.

11. Landerl, K., Wimmer, H., \& Moser, E. (1997). Salzburger Lese- und Rechtschreibtest (SLRT; 1. Auflage). Göttingen: Hogrefe.

12. Larsen, J. P., Hoien, T., Lundberg, I., \& Odegaard, H. (1990). MRI evaluation of the size and symmetry of the planum temporale in adolescents with developmental dyslexia. Brain and Language, 39, pp. 289-301

13. Lienert, G. A. (1976). Hand-Dominanz-Test. (2. Auflage). Göttingen: Hogrefe.

14. Linder, M., \& Grissemann, H. (2000). Züricher Lesetest (ZLT). (mit neuer deutscher Rechtschreibung, 6. Auflage). Göttingen: Hogrefe.

15. Lovegrove, B. (1996). Dyslexia and a transient/magnocellular pathway deficit: The current situation and future directions. Australian Journal of Psychology, 48(3), pp. 167-171.

16. Morgan, W. P. (1896). A case study of congenital word blindness. British Medical Journal, 2, pp. 1378.

17. Rathenow, P., Vöge, J., \& Laupenmühlen, D. (1980). Westermann Rechtschreibtest $6+$ (WRT 6+), 1. Auflage. Göttingen: Hogrefe.

18. Robinson, G. (2001). Investigation of biochemical anomalies in people with dyslexia: Implications for immune system dysfunction and dietary intervention. Proceedings of $5^{\text {th }}$ BDA International Conference, York

19. Schulte-Körne, G., Nöthen, M. M., \& Remschmidt, H. (1998). Genetik der LeseRechtschreibstörung (Legasthenie). Medizinische Genetik, 10, pp. 402-405.

20. Seligman, M. E.P \& Csikszentmihalyi, M. (2000). Positive Psychology: An Introduction. American Psychologist, 55 (1), pp. 5-14.

21. Slaghuis, W. L., Twell, A. J., \& Kingston, K. R. (1996). Visual and language processing disorders are concurrent in dyslexia and continue into adulthood. Cortex, 32(3), pp. 413-438.

22. Slaghuis, W. L., \& Ryan, J. F. (1999). Spatio-temporal contrast sensitivity, coherent motion, and visible persistence in developmental dyslexia. Vision Research, 39 (3), pp. 651-668.

23. Thomson, M. E. \& Hartley, G. M. (1980). Self-concept in dyslexic children. Intervention in School and Clinic, 16, pp. 19-36.

24. Tsang, S. K. M. \& Leung, C. (2005/6). Positive Psychology and enhancement of Home-School Support for Students with Dyslexia. An Evaluative Study. International Journal of learning, 2 (6), pp. 245-253.

25. Valtin, R. (1989). Dyslexia in the German language. In P. G. Aaron and R. M. Joshi (Eds.), Reading and Writing Disorders in Different Orthographic Systems. Dordrecht: Kluwer Academic Publishers, pp. 119-135.

26. Weigt, R. (1994). Lesen- und Schreibenlernen kann jeder!? Methodische Hilfen bei LeseRechtschreib-Schwäche. Neuwied, Kriftel, Berlin: Luchterhand.

27. Weiss, R. H. (1987). Grundintelligenztest Skala 2 - CFT 20. Göttingen: Hogrefe. 
28. Wilcke, A. \& Boltze, J. (2010). Genetische Grundlagen der Legasthenie. In E. Witruk, D. Riha, A. Teichert, N. Haase, \& M. Stueck (Eds.), Learning, Adjustment and Stress Disorders - With Special Reference to Tsunami Affected Regions. Frankfurt etc.: Peter Lang - Internationaler Verlag der Wissenschaften. pp. 59-82.

29. Witruk, E. (1993). Long-term Effects of Rehabilitative Interventions for Dyslexic Children. In P. Tallal, A. M. Galaburda, R. R. Llinás, \& C. von Euler (Eds.), Temporal information processing in the nervous system. Special reference to dyslexia and dysphasia. Annals of the New York Academy of Sciences, 682. New York: The New York Academy of Sciences, pp. 426-429.

30. Witruk, E. (2003). Training of working memory performance in dyslexics. Psychology Science, 45, I, pp. 94-100.

31. Witruk, E., \& Ho, C. S.-H. (in prep., 2011). Working memory in Cantonese speaking and German dyslexic children. Australian Journal of Learning Difficulties. Routledge.

32. Witruk, E., Winkler, C., \& Guenther, J. (in prep., 2011). Visual-spatial talents or compensation products in Dyslexia.

33. Witruk, E. (in prep., 2012). Impossible figures test for visual-spatial abilities. Frankfurt etc.: Peter Lang - Internationaler Verlag der Wissenschaften.

\section{Affiliations}

Prof. Dr. Evelin Witruk

University of Leipzig

Faculty of Biosciences, Pharmacy and Psychology

Institute of Psychology

Seeburgstr. 14 - 20

04103 Leipzig, Germany

eMail:witruk@rz.uni-leipzig.de 